\title{
Business Creation and the Stock Market*
}

\author{
Claudio Michelacci \\ Javier Suarez ${ }^{\dagger}$ \\ CEMFI and CEPR \\ CEMFI and CEPR
}

3 December 1999

PRELIMINARY

\begin{abstract}
We claim that the stock market encourages business creation, innovation, and growth by allowing the recycling of "informed" capital. Due to incentive problems, financing new innovative businesses requires entrepreneurs either to sustain a tight relationship with monitors (banks, venture capitalists) whose "informed" capital is in limited supply or to undertake an irreversible reorganization that makes the firm transparent enough to access the stock market. We characterize the financial life cycle of firms, showing why they choose to be initially financed through informed capital, reconsidering whether to go public once some uncertainty is resolved. We examine the efficiency properties of the competitive equilibrium and identify the factors that lead to the emergence of a stock market for young fast growing firms, facilitate the recycling of informed capital, and encourage business creation. We also show how the rate of technological progress affects and is affected by stock market development.
\end{abstract}

*Correspondence to: Claudio Michelacci a/o Javier Suarez. CEMFI, Casado del Alisal 5, 28014 Madrid, Spain. Tel: +34-91-4290551. Fax: +34-91-4291056. Email: c.michelacci@cemfi.es, suarez@cemfi.es.

†We would like to thank Jose Manuel Campa and seminar audience at CEMFI and Toulouse for helpful comments. 


\section{Introduction}

During the last two decades, the US venture capital industry has been extremely active, many young innovative companies have become major players in their corresponding industries, and there has been unprecedented growth in the liquidity and value of Nasdaq, the stock market where most young innovative companies decide to go public. This paper digs out some of the theoretical linkages between these phenomena and studies their implications for business creation, innovation, and economic growth.

There is wide consensus that venture capitalists, like some banks when involved in tight relationships with the firms that they finance, have special value for start-ups. ${ }^{1}$ They use their reputation, wealth, and expertise (in brief, their informed capital) in monitoring the activities of entrepreneurs that, due to incentive problems, have difficulties in directly raising funds among general investors. ${ }^{2}$ It has been argued that going public is crucial for profitably redirecting this capital towards new companies as it becomes less necessary to older ones. ${ }^{3}$ We bring this argument to general equilibrium and claim that by allowing the recycling of informed capital the stock market encourages business creation.

We consider an economy where new businesses are developed by entrepreneurs who are liquidity constrained. Before these businesses become profitable mature companies, their external financing is limited by a moral hazard problem. ${ }^{4}$ There are two solutions to their problem. The first requires that the entrepreneur establishes and sustains a financial relationship with a monitor. The second requires the firm to incur some irreversible (flotation) costs in order to reorganize its management control system and thereby become ready to access the more passive funding from general investors, in brief the stock market.

We model the choice between these financing alternatives along the firms'

\footnotetext{
${ }^{1}$ See for example Petersen and Rajan (1994).

${ }^{2}$ The monitoring role of special classes of financiers has been the center of the recent literature on financial intermediation, including Diamond (1991), Rajan (1992), and Holmstrom and Tirole (1997).

${ }^{3}$ See for example Black and Gilson (1998).

${ }^{4}$ Rajan and Zingales (1998) document that mature US companies are much less dependent on external finance than their younger counterparts.
} 
life cycle taking into account the equilibrium value of monitors' informed capital. Due to either the scarcity of monitoring skills or incentive problems that constrain monitors' capacity to raise funds externally, informed capital is in limited supply and tends to appropriate rents in equilibrium. ${ }^{5}$ Yet, there is some initial uncertainty on the profitability of each new firm and using informed capital may allow to postpone the decision on whether to go public till the disclosure of more precise information about the firm's prospects. Specifically, the entrepreneur faces a trade off between reorganizing a firm which might turn to be unprofitable and paying the extra cost of monitors' informed capital.

This trade off evolves along the firm's life as new information gets disclosed. If the initial uncertainty is sufficiently large, the firm chooses to be first financed through informed capital, reconsidering whether to go public after some uncertainty is resolved. At that point, the firm internalizes the fact that part of the funds raised by going public can be used to pay back its monitor, who can then redirect her informed capital towards some new business. Hence, the probability of going public depends positively on the value of informed capital.

In equilibrium the value of informed capital is higher the larger the number of entrepreneurs that seek monitors' financial support. When the economic environment becomes more favorable to entrepreneurship, informed capital becomes more valuable, and young firms decide to go public earlier, accelerating the recycling of informed capital. This goes in parallel with an endogenous increase in the size of the stock market for fast growing start-ups.

In our economy, the allocation of resources can be inefficient due to a natural incompleteness of contracts. Entrepreneurs and monitors get matched after a process of search and set the terms of their relationships through bargaining once they meet. We show that the going public decisions of the competitive economy are constrained efficient, while the equilibrium number of entrepreneurs in search for a monitor is generally not. For instance, if the ability of monitors to appropriate rents is too large, policies directed

\footnotetext{
${ }^{5}$ See Holmstrom and Tirole (1997) for further justification of why informed capital is in limited supply. They provide a static general equilibrium analysis of the allocation of informed capital among a population of heterogeneous entrepreneurs when both entrepreneurs and monitors suffer from incentive problems.
} 
to encouraging business creation can be welfare improving. We show that bringing the rule whereby the parties share the surplus of their relationships closer to the efficient one increases the equilibrium value of informed capital and thus the incentives for start-ups to go public. This has two important implications. First, the size of the stock market for young fast growing firms becomes an indicator of the economy's level of efficiency. Second, institutions that affect the ability of entrepreneurs and monitors to appropriate the rents of their relationships may explain why some countries have well-developed stock markets for young fast growing firms whereas others do not.

We extend the model in three different directions. First, we introduce technological progress. We start showing how the rate of technological progress affects the development of the stock market: the larger the rate, the larger the outside opportunities for informed capital, hence the stronger the incentives to go public. Thus a high growth rate can endogenously lead to the emergence of a stock market for young fast growing companies. The rate of technological progress, however, is not exogenous to financial development. ${ }^{6}$ We then consider the case of endogenous growth. When there are externalities in the innovation process and innovation is boosted by business creation, the development of the stock market fosters technological progress through the positive effects of the recycling of informed capital on business creation. ${ }^{7}$ This mechanism suggests a channel through which financial development may affect growth without (necessarily) affecting savings. ${ }^{8}$ Moreover a financial underdevelopment trap may emerge where growth stagnates because the stock market does not develop and the stock market does not develop because growth does not pick up.

Secondly, we consider the possibility of liquidity externalities such that the larger the number of firms listed in the market for young fast growing

\footnotetext{
${ }^{6}$ See Levine (1997) for a survey on the theoretical and empirical links between financial development and growth. Greenwood and Jovanovic (1990) develop a model where financial intermediation and growth are endogenous.

${ }^{7}$ Aghion and Tirole (1994), Greenwood and Jovanovic (1999), and Hobijn and Jovanovic (1999) provide reasons explaining why innovation may require the creation of new, independent businesses.

${ }^{8}$ Levine and Zervos (1998) provide evidence that both bank development and stock market liquidity are strongly related to productivity growth while their linkage with savings is not significant.
} 
firms the more attractive it becomes. We show that these externalities create a strategic complementarity which is a source of inefficiency in the decision to go public and can lead to the existence of multiple equilibria.

Thirdly, we endogenize the intensity of activities, such as investment banking, which are meant to accelerate the resolution of uncertainty on startups' profitability. We show that the interests vested in ongoing entrepreneurmonitor relations (which are stronger the less efficient the economy is) tend to hamper the development of investment banking, thereby endogenously delaying the recycling of informed capital and thus reducing the rate of creation of new firms. This implies that the underdevelopment of investment banking goes together with the underdevelopment of the stock market for fast growing companies.

The rest of the paper is organized as follows. In Section 2 we describe the model. Section 3 characterizes individual firm behavior. Section 4 analyzes equilibrium. In Section 5 we discuss our results on efficiency. Section 6 contains the extensions. The conclusions appear in Section 7.

\section{The model}

We consider an economy in continuous time where there is just one final good, which is the numeraire.

\section{$2.1 \quad$ Agents}

There are continuous masses $E$ of entrepreneurs, $M$ of monitors, and $I$ of investors. All of them are infinitely lived, risk neutral, and maximize the expected net present value of their income stream. Entrepreneurs have a subjective discount rate $\rho$ and are able to develop one business project per unit of time. Monitors also have a discount rate $\rho$ and can monitor one entrepreneur per unit of time. Finally, investors have a discount rate $r<\rho$ and are endowed with some (sufficiently large) exogenous flow of income that guarantees that their supply of funds is, on the relevant range, perfectly elastic at the rate $r$. The difference $\rho-r>0$ will provides a prima facie case for investors to be the financiers in this economy. 


\subsection{Technologies}

At every instant $t$, a mass $N$ of potential projects is randomly allocated among the entrepreneurs not involved in developing another project. To be operative, a project requires one unit of investment. If entrepreneurs want to keep their projects ready for the future rather than making them operative immediately, they have to incur a utility $\operatorname{cost} c$ per unit of time. Operative projects are called firms. A firm can be liquidated at any point in time at a constant liquidation value $Q \in(0,1]$. When a firm is liquidated, the underlying project is lost for ever.

There are up to two stages in a firm's life: a start-up stage, in which it does not produce any income, and a maturity stage, in which it produces an income flow $\tilde{y}$ per unit of time. A fraction $\gamma$ of the firms are good (or profitable) and have $\tilde{y}=y>0$, while the rest are bad (or unprofitable) and have $\tilde{y}=0$. Firm types are initially unknown, but they get discovered at maturity or, sometimes, before maturity.

The discovery of type and the transition to maturity are affected by a moral hazard problem: If the entrepreneur devotes his effort to the firm, its type will be early discovered and maturity will be reached according to independent Poisson processes with arrival rates $\lambda$ and $\mu$, respectively. ${ }^{9}$ Otherwise, the entrepreneur gets a flow of unverifiable private benefits from the firm, $b \leq \rho Q$, but neither maturity nor early type discovery occur. Once maturity is reached, no moral hazard problem exists.

\subsection{Financing modes}

In the absence of capital market imperfections, the entrepreneurs of this economy would never find it optimal to accumulate wealth. Since they are more impatient than the investors, $\rho>r$, they would like to borrow against the whole future income of their present and future projects and anticipate their consumption as much as possible. However, this option is not feasible because of the moral hazard problem: an entrepreneur without a stake in the project's future income would prefer the stream of private benefits $b$

\footnotetext{
${ }^{9}$ Of course, when project type is discovered before maturity, the entrepreneur's effort is still needed to reach maturity.
} 
to contributing his effort during the start-up stage and, anticipating this, nobody would finance the project.

A solution might be to finance the project, at least in part, with the entrepreneur's own funds. In our economy, however, this solution does not work if $N$ is small relative to $E$, as we indeed assume. The reason is that if an entrepreneur has very few chances to get a project, the difference between the discount rate $\rho$ and the market interest rate $r$ will dissuade him from accumulating any wealth.

We consider two external financing solutions. The first is informed capital financing, which consists in the establishment of a tight relationship with an expert monitor. (So we indistinctly refer to $M$ as the number of monitors and the stock of informed capital in the economy.) We assume that the monitor may obtain enough information and control on the entrepreneur to guarantee that he devotes his effort to the firm. ${ }^{10}$ For simplicity and without loss of generality, we assume that monitors finance entrepreneurs with their own funds. ${ }^{11}$ Moreover, we assume that the provision of the funds for a project occurs at the point the monitor starts a relationship with an entrepreneur. ${ }^{12}$

The second solution is stock market financing, which comes from investors. Investors provide funds at a rate $r<\rho$ that reflects the advantages in terms of liquidity and risk diversification that associate with the issuance of public securities vis-a-vis the private securities used in entrepreneur-monitor relationships. However, since investors do no provide active monitoring, we assume that going public before maturity requires reorganizing the firm and imposing a management control system effective enough to guarantee (once and for all) that the entrepreneur is diligent. This reorganization involves an

\footnotetext{
${ }^{10}$ Following Holmstrom and Tirole (1997), one could argue that monitors run a technology that reduces the flow of private benefits associated with shirking, making it unprofitable to the entrepreneur. In a more classical sense, monitoring might consist in making the entrepreneur's actions verifiable so as to enforce penalties in case of misconduct.

${ }^{11}$ As in Holmstrom and Tirole (1997), this could be motivated by incentive problems at the level of the monitors.

${ }^{12}$ Given the difference between $\rho$ and $r$, monitors want to commit as less wealth as possible to their activity. Monitors may form coalitions (such as banks or venture capital funds) that pool together the cash flows involved in a large number of relationships. With such an arrangement, monitors may diversify away projects' idiosyncratic risk and guarantee the instantaneous availability of funds for their new relationships.
} 
unrecoverable flotation cost $F .^{13}$

\subsection{Search frictions}

The process whereby entrepreneurs access to informed capital financing is subject to search frictions. The underlying assumption is that projects are heterogeneous and monitors are specialized in monitoring specific subsets of the possible projects. Since evaluating whether the characteristics of a project match the ability of a given monitor takes time, matching an entrepreneur with a suitable monitor also requires time.

Following Pissarides (1990), we model the rate at which entrepreneurs match with suitable monitors using a homogeneous-of-degree-one matching function $h\left(e_{t}, m_{t}\right)$, where $e_{t}$ and $m_{t}$ denote, respectively, the number of entrepreneurs searching for a monitor and of monitors searching for an entrepreneur at time $t$. This function is assumed to be increasing and concave in each of its arguments. Accordingly, an entrepreneur will find a suitable monitor at the rate

$$
q\left(\theta_{t}\right)=\frac{h\left(e_{t}, m_{t}\right)}{e_{t}}=h\left(1, \frac{1}{\theta_{t}}\right),
$$

which is decreasing in $\theta_{t}=e_{t} / m_{t}$. Analogously, a free unit of informed capital will find a project to finance at the rate $\theta_{t} q\left(\theta_{t}\right)$, which is increasing in $\theta_{t}$. This allows us to interpret $\theta_{t}$ as an indicator of the level of credit rationing in the economy. ${ }^{14}$ We further assume

$$
\lim _{x \rightarrow 0} q(x)=\lim _{x \rightarrow \infty} x q(x)=\infty \text { and } \lim _{x \rightarrow \infty} q(x)=\lim _{x \rightarrow 0} x q(x)=0,
$$

in order to guarantee that the equilibrium value of $\theta_{t}$ is interior.

\subsection{Contracts}

If an entrepreneur and a suitable monitor who have just met separated, each would have to go through a time-consuming process of search before

\footnotetext{
${ }^{13}$ The Appendix provides the condition under which the private benefits $b$ render the recourse to straight stock market financing (without paying $F$ ) unfeasible before maturity.

${ }^{14}$ Search frictions generate a situation that fits into the formal definition of equilibrium credit rationing (see Baltensperger, 1976): entrepreneurs willing to borrow from monitors at the terms that prevail in equilibrium are (temporarily) unable to obtain credit.
} 
meeting a new suitable partner. Hence, there is some surplus from starting a relationship. The contract that the entrepreneur and the monitor sign makes them share this surplus. For simplicity, we focus on straight equity contracts whereby they will receive a fraction $\alpha$ and $1-\alpha$, respectively, of any net revenue generated during their relationship. We assume that both $\alpha$ and the conditions upon which the firm will go public or be liquidated are determined at the beginning of the relation using a generalized Nash bargaining rule in which the bargaining powers of the entrepreneur and the monitor are $\beta \in(0,1)$ and $1-\beta$, respectively.

\section{The financial life cycle of firms}

We have introduced two financing modes: informed capital financing and stock market financing. Given the greater opportunity cost of monitors' funds, stock market financing dominates if flotation costs are zero. This is actually the case once firms mature. Among start-ups, however, there is a trade-off between the cost $F$ of going public and the gains associated with, first, the difference between $\rho$ and $r$ and, second, the possibility of reusing the informed capital involved in the current entrepreneur-monitor relation.

When firms start up their types are unknown. Some are discovered to be good or bad at maturity only. Others get their types discovered before maturity. We need to analyze their financing decisions in every possible state. Start-ups which are discovered to be bad, at or before maturity, will be liquidated. Good start-ups which reach maturity will produce under stock market financing. The cases of the start-ups of unknown type and the startups that get their type discovered to be good before maturity require further discussion.

\subsection{The need for informed capital}

If entrepreneurs decided to finance their start-ups of unknown type by directly going public, no firm would ever use informed capital in this economy. We focus, instead, in the more interesting (and realistic) situation where $F$ is large enough to rule out the access to stock market financing at such an early stage. 
Suppose that the investors value at $R^{0}$ the future income from an unknown start-up to which the entrepreneur devotes his effort. Since buying the machine and solving the moral hazard problem costs $1+F$, directly going public will not be feasible if $R^{0}-1-F<0$. Let the investors' value of the income of a good firm at maturity and at the early discovery of its type be denoted by $Y=\frac{y}{r}$ and $R^{d}=\frac{\mu}{\mu+r} Y$, respectively. Then, after computing $R^{0},{ }^{15}$ we find a critical value

$$
F^{0}=\frac{\lambda\left[\gamma R^{d}+(1-\gamma) Q\right]+\mu R^{m}}{\lambda+\mu+r}-1,
$$

with $R^{m}=\gamma Y+(1-\gamma) Q$, such that if

$$
F>F^{0}
$$

start-ups of the unknown type cannot directly access stock market financing.

Under (3) entrepreneurs will have to rely on informed capital to start up their projects, postponing the going public decision to either maturity (where there is no doubt on the optimality of going public) or the early discovery of their firms' type. We analyze the latter decision below, in the context of the entrepreneur-monitor relationship.

\subsection{The entrepreneur-monitor relationship}

Consider what happens when an entrepreneur who is trying to finance a project of unknown quality meets a monitor who has the informed capital necessary to do so. They have to agree on the sharing rule $\alpha \in[0,1]$ according to which they will divide the revenue generated during their relationship. They also have to decide whether the start-up will go public in case it is discovered to be good before maturity. We formally represent this financial life cycle decision by the probability $f \in[0,1]$ of going public at that point.

Let $B^{u}$ and $L^{u}$ respectively denote the entrepreneur's and the monitor's value of a relationship in which the firm type is unknown. According to the

\footnotetext{
${ }^{15}$ To compute $R^{0}$, think of a firm of unknown type as an asset whose returns are described by the equation $r R^{0}=\lambda\left(R^{d}-R^{0}\right)+\mu\left(R^{m}-R^{0}\right)$. Similarly, $R^{d}$ can be obtained solving $r R^{d}=\mu\left(Y-R^{d}\right)$, and $Y$ solving $r Y=y$.
} 
generalized Nash bargaining rule, $\alpha$ and $f$ will solve

$$
\max _{(\alpha, f) \in[0,1] \times[0,1]}\left(B^{u}-U\right)^{\beta}\left(L^{u}-1-V\right)^{1-\beta},
$$

where $U$ and $V$ are the values of the outside options of each party, which from the point of view of the maximization are taken as constants, and -1 accounts for the funds provided by the monitor in order to make the project operative. ${ }^{16}$

The entrepreneur's value of the relationship solves

$$
\begin{aligned}
\rho B^{u}= & \lambda\left[\gamma f \alpha\left(R^{d}-F\right)+\gamma(1-f) B^{d}+(1-\gamma) \alpha Q-B^{u}\right] \\
& +\mu\left(\alpha R^{m}-B^{u}\right),
\end{aligned}
$$

where the first term captures the capital gain associated with the early discovery of type and the second the capital gain at maturity. To explain the first, notice that if the firm is discovered to be bad it gets liquidated at a value $Q$. If, on the other hand, it is discovered to be good, it goes public with probability $f$, which yields a total net revenue of $R^{d}-F$, while the relationship is continued with probability $1-f$, which has a value $B^{d}$ to the entrepreneur. This value solves

$$
\rho B^{d}=\mu\left(\alpha Y-B^{d}\right),
$$

reflecting that, once the good firm matures, going public yields a total revenue of $Y$ and the relationship with the monitor terminates.

Analogously, the monitor's value of the relationship while firm type is unknown solves

$$
\begin{aligned}
\rho L^{u}= & \lambda\left[\gamma f(1-\alpha)\left(R^{d}-F\right)+\gamma(1-f) L^{d}+(1-\gamma)(1-\alpha) Q-L^{u}\right] \\
& +\mu\left[(1-\alpha) R^{m}-L^{u}\right]+[\lambda+\mu-\lambda \gamma(1-f)] V
\end{aligned}
$$

The first two terms in the right hand side are symmetric to those in (5). The new third term reflects the recycling of informed capital, worth $V$, that takes place when the relationship with the entrepreneur breaks up. This occurs upon the arrival of any news, except if the firm is discovered to be good

\footnotetext{
${ }^{16}$ In the next section, we discuss how the values of $U$ and $V$ are determined in equilibrium.
} 
before maturity in which case there is a probability $1-f$ that the relation continues. The monitor's value of continuing the relation after the firm is early discovered to be good, $L^{d}$, is given by

$$
\rho L^{d}=\mu\left[(1-\alpha) Y+V-L^{d}\right] .
$$

The first order condition for the choice of $\alpha$ in (4) implies that

$$
\begin{gathered}
B^{u}=U+\beta S, \\
L^{u}=1+V+(1-\beta) S,
\end{gathered}
$$

where $S=\left(B^{u}+L^{u}-1\right)-(U+V)$ represents the surplus from starting the entrepreneur-monitor relationship.

Given (4), (9) and (10), the parties will agree on the financial life cycle decision $f$ that maximizes $S$. To obtain an expression for $S$ conditional on $f$, we first add up (5) and (7), using (6) and (8). Then we group together the terms which include $B^{u}+L^{u}$ and add and subtract constants so as to replace them with $S$. This yields:

$$
\begin{aligned}
S= & \frac{\lambda}{\lambda+\mu+\rho}\left[\gamma f\left(R^{d}-F\right)+\gamma(1-f)\left(R^{w}-\frac{\rho}{\mu+\rho} V\right)+(1-\gamma) Q\right] \\
& +\frac{\mu}{\lambda+\mu+\rho} R^{m}-\frac{\rho}{\lambda+\mu+\rho} V-U-1 .
\end{aligned}
$$

where $R^{w}=\frac{\mu}{\mu+\rho} Y$ represents the sum of the entrepreneur's and the monitor's value of the revenue that they will receive if the start-up which is known to be good is sold to investors at its maturity.

The surplus $S$ is affected linearly by financial life cycle decision $f$. Deriving with respect to $f$ in (11) identifies a critical value

$$
F^{d}=\frac{(\rho-r) \mu Y}{(\mu+\rho)(\mu+r)}+\frac{\rho V}{\mu+\rho}
$$

such that it is optimal to set $f$ according to the rule

$$
f= \begin{cases}1 & \text { if } F \leq F^{d} \\ 0 & \text { otherwise }\end{cases}
$$

The expression for $F^{d}$ shows that the going public decision of a start-up that gets its type discovered to be good produces two gains. The first is a liquidity 
gain because going public allows the entrepreneur and the monitor to profit earlier from the lower discount rate that reflects the greater liquidity of the financial positions of the investors. Investors are willing to buy the firm at a price $R^{d}$ once its type has been discovered to be good (and $F$ has been paid), while the entrepreneur's and monitor's value of the revenue that they will receive by selling the firm at maturity adds up to $R^{w}<R^{d}$ since $\rho>r$. The second is a recycling gain because going public frees the informed capital of the monitor, worth $V$, immediately rather than at maturity. The discount factor $\frac{\rho}{\mu+\rho}$ accounts for the expected cost of the time till maturity.

The presence of $V$ in (12) and its subsequent influence on the choice of $f$ indicates the "endogeneity" of firms' financial life cycle in this model and identifies the source of an interesting feedback that we further analyze in the next section: equilibrium $V$ will both determine and be determined by the speed of recycling of informed capital associated with the endogenous going public decisions of start-ups.

\section{Equilibrium}

The equilibrium in our economy can take three possible configurations, depending on whether the creation of new firms (that will be the source of growth in aggregate output) is ultimately constrained by the stock of informed capital $M$, the flow of new projects $N$, or both. We are going to focus on the first of these configurations by assuming that $M$ is small relative to $N$.

Formally, an equilibrium is a level of credit rationing $\theta \in[0, \infty)$ and a contract $(\alpha, f) \in[0,1] \times[0,1]$ governing each entrepreneur-monitor relationship, such that no privately profitable business opportunities remain unexploited. With $M$ small relative to $N$, the latter requirement means that, in addition to $(\alpha, f)$ being fixed according to (9)-(13), a free entrepreneur's value from searching must be zero, $U=0$, while a free monitor's value from searching must be positive, $V \geq 0$.

We characterize the unique equilibrium of our economy by reducing the different equilibrium conditions to a single equation that uniquely determines $\theta$. The discussion will focus on the equilibrium $\theta$ and the unique equilibrium 
life cycle $f$ associated with it. Afterwards we analyze the equilibrium rate of creation of new businesses, commenting on the incidence of financial imperfections and flotation costs on this rate.

\subsection{Credit rationing and the financial life cycle}

The values from searching, $U$ and $V$, solve the equations

$$
\begin{aligned}
& \rho U=-c+q(\theta)\left(B^{u}-U\right), \\
& \rho V=\theta q(\theta)\left(L^{u}-1-V\right),
\end{aligned}
$$

where $c$ measures the utility cost required for an entrepreneur to maintain his project during the process of search, $q(\theta)$ and $\theta q(\theta)$ account for the rates at which the corresponding agent finds a partner with whom to start a relationship, and $B^{u}-U$ and $L^{u}-1-V$ measure each party's net gain from starting the relationship.

The solution to the bargaining problem, (9) and (10), allows us to write (14) and (15) as

$$
\begin{gathered}
\rho U=-c+q(\theta) \beta S, \\
\rho V=\theta q(\theta)(1-\beta) S .
\end{gathered}
$$

Then $U=0$ implies

$$
\rho V=\frac{1-\beta}{\beta} c \theta
$$

which substituted in (12) yields

$$
F^{d}(\theta)=\frac{(\rho-r) \mu Y}{(\mu+\rho)(\mu+r)}+\frac{(1-\beta) c \theta}{(\mu+\rho) \beta},
$$

where $\theta$ is the only endogenous variable.

This expression together with (13) allows us to account for the optimal choice of $f$ in (11). Then, with $U=0$ and using (17) to substitute for $V$, we obtain

$$
S(\theta)=\frac{\lambda\left\{\gamma R^{d}-\gamma \min \left[F, F^{d}(\theta)\right]+(1-\gamma) Q-1\right\}+\mu\left(R^{m}-1\right)-\rho}{\lambda+\mu+\rho+(1-\beta) \theta q(\theta)}
$$


where again $\theta$ is the only endogenous variable. Notice that $S(\theta)$ is strictly decreasing in $\theta$ since both $F^{d}(\theta)$ and $\theta q(\theta)$ are strictly increasing in $\theta .{ }^{17}$

Finally, given $S=S(\theta)$, imposing $U=0$ in (16) leads to the equilibrium free-entry condition for entrepreneurs:

$$
\beta q(\theta) S(\theta)=c
$$

The left hand side of this equation is continuous and strictly decreasing in $\theta$; moreover, $\lim _{x \rightarrow \infty} q(x) S(x)=0$ and $\lim _{x \rightarrow 0} q(x) S(x)=\infty$, by (1). So (21) does always have a unique solution $\theta \in(0, \infty)$. (Notice also that $\theta>0$ and (18) implies, as required, $V>0$.)

Given the solution for equilibrium $\theta$ that arises from (21), one can determine the (generically) unique equilibrium financial life cycle of firms, $f$ by using (13) and (19). ${ }^{18}$

\subsection{The equilibrium rate of business creation}

In our economy the existence of a moral hazard problem during the start-up stage together with the excessive cost of going public before a firm is known to be good, condition (3), imply the need for informed capital. If the stock of informed capital $M$ is small relative to the flow of new projects $N$, the creation of new firms ends up constrained by the former. We show below how this constraint relates to the equilibrium values of $\theta$ and $f$, and thereby to the parameters (most notably, $F$ ) that determine them.

Let $u_{t}$ denote the pool of start-ups of unknown type (all of which are in a entrepreneur-monitor relationship) and let $d_{t}$ denote the pool of start-ups discovered to be good which remain in a relationship. Then the stock of free informed capital at time $t$ will be $m_{t}=M-d_{t}-u_{t}$ and the flow of newly created firms at time $t$ will be

$$
n_{t}=\theta q(\theta)\left(M-d_{t}-u_{t}\right)
$$

since each free unit of informed capital matches with a suitable entrepreneur at the rate $\theta q(\theta)$.

\footnotetext{
${ }^{17}$ This argument implicitly assumes that $S(\theta)$ is positive for all $\theta$. A sufficient condition for this is: $\lambda\left[\gamma R^{d}-\gamma F+(1-\gamma) Q-1\right]+\mu\left(R^{m}-1\right)-\rho>0$.

${ }^{18}$ Similarly, one can determine the unique equilibrium value of $\alpha \in(0,1)$ using equations (5)-(10). We omit the details for brevity.
} 
The evolution of $u_{t}$ is in turn driven by the entry of the newly created firms and the exit of those that either mature or get their type discovered. Thus,

$$
\dot{u}_{t}=n_{t}-(\lambda+\mu) u_{t} .
$$

Analogously $d_{t}$ is increased by the flow of start-ups discovered to be good that do not go public and decreased by the exit of those that reach maturity, SO

$$
\dot{d}_{t}=\lambda \gamma(1-f) u_{t}-\mu d_{t}
$$

Setting $\dot{d}_{t}=\dot{u}_{t}=0$ in the previous equations, we obtain the steady-state rate of creation of new firms:

$$
n=\theta q(\theta) m=\frac{\theta q(\theta)(\lambda+\mu) M}{\lambda+\mu+\left[1+\frac{\lambda \gamma}{\mu}(1-f)\right] \theta q(\theta)},
$$

which is the product of the rate at which one unit of free informed capital finds a project to finance, $\theta q(\theta)$, and the stock of free informed capital in steady state, $m$. Note that $m$ is larger the quicker the informed capital used in relationships gets recycled (the larger $f$ ).

The rate $n$ is important since a fraction $\gamma$ of the newly created start-ups eventually become mature good firms, so in steady state the pool of mature good firms and aggregate income (the output they produce) will grow linearly at the rates $\gamma n$ and $\gamma y n$ respectively. ${ }^{19}$ The rate $n$ can be compared with what it would be in the absence of the moral hazard problem, $\tilde{n}=N$, or in the absence of search frictions, $\hat{n}=\left[1+\frac{\lambda \gamma}{\mu}(1-\hat{f})\right]^{-1}(\lambda+\mu) M$, where $\hat{f} \geq f$ denotes the going public decision of discovered-good start-ups that would characterize such an economy. ${ }^{20}$ Clearly $\tilde{n}>\hat{n}>n$, which means that both the moral hazard problem that affects the start-ups and the frictions that

\footnotetext{
${ }^{19}$ This economy exhibits linear rather than exponential growth. In section 8 we model explicitly the externalities that are required to sustain exponential growth.

${ }^{20}$ The life cycle decision $\hat{f}$ is driven by (12) and (13), as in our economy. What makes the problem different is the different equilibrium value of informed capital without search frictions, say $\hat{V}$. If entrepreneurs and monitors match immediately, they do not need to be compensated for any cost incurred during the process of search, hence $0=\hat{U}=\hat{B}^{u}$ and $\hat{V}=\hat{L}^{u}-1$ and all the net revenue from a relationship, $\hat{B}^{u}+\hat{L}^{u}-1$, will be appropriated by the monitor. Since this revenue is no smaller than in our economy, we have $\hat{V}=$ $\hat{B}^{u}+\hat{L}^{u}-1 \geq B^{u}+L^{u}-1>U+V=V$, which implies $\hat{f} \geq f(\theta)$.
} 
affect their search for informed capital have a negative impact on growth. ${ }^{21}$

Importantly, the various parameters that describe the financial structure of the economy (e.g., $F, M$, and the difference between $\rho$ and $r$ ) have an influence on business creation and growth. Consider, for instance, the effect of an increase in the flotation cost $F$. Suppose that in equilibrium $F<F^{d}(\theta)$, so $f=1$. From (20), increasing $F$ decreases $S(\theta)$ and, thereby, has a negative impact on the profitability of entrepreneurship, $U$. Then, from (21), restoring the equilibrium requires a lower level of credit rationing. However, a lower $\theta$ implies that the free units of informed capital will match with entrepreneurs at a lower rate. As a consequence, the steady state rate of business creation $n$ will fall.

The negative effect on growth of an increase in $F$ is more dramatic when it alters the financial life cycle of the firms. Notice that as $F$ increases, $\theta$ decreases, so $V$ decreases and $F^{d}(\theta)$ also decreases. So eventually $F>F^{d}(\theta)$ which will discourage good start-ups from going public. But switching to $f=$ 0 means that informed capital gets stuck for longer in ongoing relationships, so the steady state stock of free informed capital $m$ and, hence, the steady state rate of creation of new firms $n$ will fall. ${ }^{22}$

\section{$5 \quad$ Efficiency}

In this section we compare the competitive equilibrium of our economy to the constrained social optimum. Since the welfare of the population of investors is invariant to the equilibrium allocation, we define the social welfare function as the present discounted utility of the aggregate consumption flows of the monitors and the entrepreneurs, $W$. The social planner will take as given the moral hazard problem inherent in financing a start-up as well as the search frictions involved in allocating informed capital. At any point in time, the state of the economy is fully summarized by the quantities $u_{t}$ and $d_{t}$ that

\footnotetext{
${ }^{21}$ We do not emphasize the role of search frictions in reconciling cross-sectional or time series variation in growth. Yet, our results identify an interesting avenue for further both theoretical and empirical research.

${ }^{22}$ Rajan and Zingales (1998) and Kumar et al. (1999) provide evidence that suggests accounting standards as an empirically relevant source of cross-country variability for our parameter F. Specifically, they find that country-specific accounting standards strongly interact with the industry-specific need of external financing in explaining industry growth.
} 
represent, respectively, the pools of unknown start-ups and of good start-ups that remain financed through informed capital after being early discovered to be so. Without loss of generality, we consider time invariant allocations described by a level of credit rationing $\theta$ and a financial life cycle $f .{ }^{23}$ The social welfare function can then be written as a function $W(u, d ; \theta, f)$ which satisfies

$$
\begin{aligned}
\rho W\left(u_{t}, d_{t} ; \theta, f\right)= & \left\{\lambda\left[\gamma f\left(R^{d}-F\right)+(1-\gamma) Q\right]+\mu R^{m}\right\} u_{t}+\mu Y d_{t} \\
& -[c \theta+\theta q(\theta)]\left(M-d_{t}-u_{t}\right)+z^{u} \dot{u}_{t}+z^{d} \dot{d}_{t}
\end{aligned}
$$

where $z^{u}=\frac{d W}{d u_{t}}$ and $z^{d}=\frac{d W}{d d_{t}}$ indicate the marginal contributions to welfare of an unknown and a good start-up, respectively, while $\dot{u}_{t}$ and $\dot{d}_{t}$ are described by (23) and (24) respectively.

Now we can prove our first result on efficiency: that conditional on the level of credit rationing $\theta$, the financial life cycle of firms in the competitive equilibrium is socially efficient. In the Appendix we show that fully differentiating in (26) with respect to $f$ yields

$$
\begin{array}{lll}
\frac{d W}{d f}<0 & \text { if } & F>F^{d}(\theta), \\
\frac{d W}{d f}>0 & \text { if } & F<F^{d}(\theta),
\end{array}
$$

which means that the social planner's rule for the choice of $f$ coincides with the rule (13) that entrepreneurs and monitors use to decide $f$ at the beginning of their relationships.

The same cannot be said about the equilibrium level of credit rationing. To see this, let $\eta=\frac{1}{q(\theta)} \frac{d[\theta q(\theta)]}{d \theta}$ denote the elasticity of the matching function with respect to the number of entrepreneurs that search for monitors, which is a measure of the marginal contribution of the former to the creation of new businesses. In the Appendix we show that, in steady state, the equilibrium value of $\theta$ will be lower (higher) than socially optimal if the entrepreneurs'

\footnotetext{
${ }^{23}$ Under a time invariant configuration of parameters, neither the competitive equilibrum nor the solution to the social planner problem will exhibit time variation in $\theta$ and $f$. In principle such variation might be induced by the evolution of the state variables. However, neither the equilibrium (as seen in the previous section) nor the social optimum (as can be deduced from the analysis below) imply values of $\theta$ and $f$ that depend on $u$ and $d$. So the analysis that follows implies no loss of generality.
} 
bargaining power $\beta$ is lower (higher) than $\eta$. Formally,

$$
\begin{array}{llll}
\frac{d W}{d \theta}<0 & \text { if } & \beta>\eta, \\
\frac{d W}{d \theta}>0 & \text { if } & \beta<\eta .
\end{array}
$$

To explain this, notice that our economy allocates informed capital to projects in a highly decentralized fashion. When a entrepreneur meets with a suitable monitor the surplus of their relationship is divided according to the sharing rule implied by the bargaining powers $\beta$ and $1-\beta$. Ex ante the sharing rule plays a crucial role in encouraging or discouraging entrepreneurs with projects to search for a monitor. However, opposite to a Walrasian price, $\beta$ and $1-\beta$ may not adjust to reflect the scarcity or the marginal social value of a searching entrepreneur or a searching monitor. The equilibrium yields an efficient level of credit rationing only when, by coincidence, $\beta=\eta{ }^{24}$

If $\beta<\eta$, monitors are "too strong" in the sense that entrepreneurs appropriate too little surplus (relative to the first best) and enter the process of search at an inefficiently low level, hence $\theta$ is too low. If so, policies aimed at directly encouraging entrepreneurship can be welfare improving. This rationalizes the view according to which having a "too strong" banking sector may be an obstacle for entrepreneurship and growth, and may justify policies oriented to increase the number of entrepreneurs.

An alternative way of increasing efficiency might be to reform the institutions that determine the division of the surplus or, in model terms, the distribution of bargaining power as parameterized by $\beta$. On this respect, our previous result means that reaching efficiency would require making $\beta=\eta$. We prove in the Appendix that, when setting $\beta=\eta$, not only welfare but also the equilibrium value of informed capital, $V$, reaches a (local) maximum. But from (12), this implies that $F^{d}$ also reaches a maximum; in words: an economy with an efficient division of the surplus valuates the recycling role of the stock market more than those with an inefficient one. Therefore, for given $F$, reforms which improve the allocation of resources by changing the division of the surplus will encourage firms to go public earlier. Similarly,

\footnotetext{
${ }^{24}$ The result that, in an economy with search frictions, the allocation of resources is constrained efficient when bargaining powers reflect the contribution of each side to the creation of new relations is originally due to Hosios (1990); see also Pissarides (1990).
} 
the institutions behind such a division, as the level of competition among monitors or the extent to which their informational monopolies are legally protected, may explain the emergence or not of a market for young fast growing companies such as, for example, Nasdaq in the US.

This finding may throw some light on a question that has been repeatedly raised in Europe: Is the lack of a well-functioning market for young fast growing companies a cause of the apparent weakness of European entrepreneurship? ${ }^{25}$ If the lack of a stock market for fast growing companies is due to some exogenous deficit in terms of financial integration and regulation that makes $F$ larger in Europe than in the US, the answer is yes, according to the results obtained at the end of Section 4. Yet our findings in this section suggest that the "problem" of Europe might come from some deeper inefficiency in the allocation of resources. With $\beta<\eta$ the lack of a market for young fast growing companies might just be one more effect of the problem that causes the lack of entrepreneurship, reduces the value of informed capital, and discourages firms from going public early.

\section{Extensions}

\subsection{Growth}

We think that our model has implications for the linkage between financial development and growth. For the recycling role of the stock market to be empirically relevant for innovation and growth two conditions must be satisfied. First, some innovations must require the creation of new businesses. Aghion and Tirole (1994), Greenwood and Jovanovic (1999), and Hobijn and Jovanovic (1999) provide reasons explaining why at least part of the innovations cannot occur inside the corporations that already exist. ${ }^{26}$ Secondly,

\footnotetext{
${ }^{25}$ According to a Communication of the European Comission (1998, p.1), "what is at stake is the creation of a new entrepreneurial culture in Europe. The real political challenge is to provide the tools, enabling technologies and financial instruments for a new generation of European entrepreneurs to start up and succeed."

${ }^{26}$ For instance, Aghion and Tirole (1994) consider the holdup problem that affects the relationship between an innovator and the potential user of the innovation. They show that, when the incentives of the innovator are important, the optimal solution involves making him the owner of his innovation, that is, creating a new firm.
} 
business creation must be effectively constrained by the availability of informed capital. We think that this condition is likely to be the case during technological revolutions, when investment opportunities flourish under the impetus of new products and technologies. ${ }^{27}$

In this extension we look at the implications for growth by introducing technological progress in the model. First, we analyze its impact on financial development by examining its effects on the financial life cycle of start-ups. Secondly, we endogenize the rate of technological progress by making explicit the role played by business creation in innovation.

\subsubsection{The effect of growth on financial development}

Assume that all relevant quantities in the life of a firm are scaled up by a factor $X_{t}$ that identifies the state of technology at time $t$ and, due to technological progress, grows at a constant exponential rate $g=\frac{\dot{X}_{t}}{X_{t}}<r$. Thus, at time $t$, the investment required to make a project operative is $X_{t}$, the liquidation value of a firm is $Q_{t}=Q X_{t}$, the flow of private benefits that the manager can obtain in case of misconduct is $b_{t}=b X_{t}$, and the cost of going public is $F_{t}=F X_{t}$. Analogously, if a firm successfully reaches maturity at time $t$ its output is $y_{t}=y X_{t}$ from that time onwards.

This economy has a balanced-growth equilibrium where aggregate output is

$$
O_{t}=\int_{-\infty}^{t} y X_{s} \dot{k}_{s} d s=\frac{y \gamma n}{g} e^{g t}
$$

which grows at rate $g$, while both the level of credit rationing $\theta$ and the contract $(\alpha, f)$ that governs entrepreneur-monitor relationships are constant over time. As in the basic model, we can reduce the different equilibrium conditions to a single equation that uniquely determines $\theta$ and then obtain $f$ recursively.

\footnotetext{
${ }^{27}$ These two conditions seem to apply well to the current wave of technological progress. For example Kortum and Lerner (1998) attribute the recent jump in patenting in the US to a sharpe increase in innovation. Moreover, Krusell et al. (1999) note a significant increase in the rate of technological change which is investment specific. In particular they observe that the rate of technological change that is specific to capital equipment has been 2.7 percentage higher after 1975 than before. The acceleration in the rate of technological progress is commonly attributed to the 'IT revolution'. Greenwood and Jovanovic (1999) and Hobijn and Jovanovic (1999) argue that, differently from the previous technological revolutions, IT has mainly benefited newly created firms rather than incumbents.
} 
Specifically, the value at time $t$ of the surplus of a relationship in which firm type is unknown is given by the product of $X_{t}$ and the quantity

$$
S(\theta, g)=\frac{\lambda\left\{\gamma R^{d}(g)-\gamma \min \left[F, F^{d}(\theta, g)\right]+(1-\gamma) Q-1\right\}+\mu\left(R^{m}-1\right)-\rho+g}{\lambda+\mu+\rho-g+(1-\beta) \theta q(\theta)}
$$

where $R^{d}(g)=\frac{\mu Y}{\mu+r-g}$ and

$$
F^{d}(\theta, g)=\frac{(\rho-r) \mu Y}{(\mu+\rho-g)(\mu+r-g)}+\frac{(1-\beta) c \theta}{(\mu+\rho-g) \beta} .
$$

After scaling up by $X_{t}$, these quantities have the same interpretation as our previous variables $S(\theta), R^{d}$, and $F^{d}(\theta)$. Notice also that both $S(\theta, g)$ and $F^{d}(\theta, g)$ are increasing in $g$.

The equilibrium level of credit rationing $\theta$ is the unique solution to the free entry condition for entrepreneurs:

$$
\beta q(\theta) S(\theta, g)=c,
$$

while the firms' s financial life cycle is determined by the rule

$$
f(\theta, g)= \begin{cases}1 & \text { if } F \leq F^{d}(\theta, g) \\ 0 & \text { otherwise }\end{cases}
$$

analogous to (13). To see the effect of a change in the rate of technological progress $g$ on the equilibrium, notice that, for given $\theta$, if $g$ increases, the surplus of entrepreneur-monitor relationships $S(\theta, g)$ increases. But then the profitability of becoming an entrepreneur also increases, so restoring the free entry condition implies that the equilibrium level of credit rationing $\theta$ must rise.

As a result of the higher $g$ and the higher $\theta, F^{d}(\theta, g)$ goes up making more likely that start-ups go public. This means that, higher growth brings more profitable opportunities for informed capital thus raising the incentives to develop a stock market for young companies. As a result, the rate of technological progress positively affects the development of financial markets.

\subsubsection{Endogenous growth}

We now endogenize the rate of technological progress $g$ by introducing a positive externality related to the success of new businesses. We assume that 
every time a firm successfully reaches maturity, it induces an (intertemporal) externality which improves the state of technology $X_{t}$ of all start-ups. More specifically, we assume that $X_{t}$ grows at a rate proportional to the density of firms that successfully reach maturity $\dot{k}_{t} \cdot{ }^{28}$ In steady state $\dot{k}_{t}=\gamma n$, hence the rate of technological progress $g$ is, by (25),

$$
g=\sigma \gamma n=\frac{\sigma \gamma(\lambda+\mu) \theta q(\theta) M}{\lambda+\mu+\left\{1+\frac{\lambda \gamma}{\mu}[1-f(\theta, g)]\right\} \theta q(\theta)},
$$

where $\sigma$ measures the size of the innovation (and its associated externality). Notice from (31) that the equilibrium financial life cycle is given by $f(\theta, g)$, which is increasing in its two arguments. Then (30) and (32) solve for the steady-state equilibrium of our economy in the $\theta-g$ space. (32) defines a positive relation between the steady state growth rate of the economy and the equilibrium level of credit rationing. The larger is $\theta$, the larger the rate of business creation and the larger the probability $f$ that good start-ups go public. Hence the larger is the rate of technological progress $g$. It also follows from the analysis of the previous section that (30) defines a positive relation between $\theta$ and $g$. The larger the rate of technological progress, the larger is the profitability of entrepreneurship and so is $\theta$. Hence when the rate of technological progress and the development of financial markets are both endogenous, growth might stagnate because the stock market does not provide enough recycling of informed capital and this, in turn, is so because of the lack of growth. When this happens the economy falls in what might be identified as a financial underdevelopment trap.

\subsection{Liquidity externalities}

Our stock market for good start-ups resembles a stock market for young fast growing companies like Nasdaq in the US. The analysis in the previous

\footnotetext{
${ }^{28}$ This follows Caballero and Jaffe (1993) and Aghion and Howitt (1998), among others. A natural interpretation is that there is a continuum of increasingly productive techniques indexed by a real number which corresponds to the log of its productivity parameter. Maturity means that the good firm has succeeded in discovering a new technique and all start-ups can hereafter search for the next technique in the continuum. So, at any point in time, the rate of technological progress is proportional to the flow of firms that reach maturity at that time.
} 
sections has already delivered some possible answers to the question on why that type of market might or might not emerge. In this extension we explore an alternative answer based on liquidity externalities that create a strategic complementarity in the going public decisions of start-ups and can lead to the existence of multiple equilibria. The analysis identifies fragmentation as a possible cause for stock market underdevelopment and provides a rational for subsidizing IPO's.

Nasdaq has been claimed to be just an 'IT facility' that allowed previously fragmented over-the-counter markets to merge into an increasingly liquid one. ${ }^{29}$ Its success points out to the importance of liquidity externalities in determining the attractiveness of a market. A possible way of capturing them in our model is to assume that the flotation $\operatorname{cost} F$ is negatively related to the number of start-ups discovered to be good that are public, $p{ }^{30}$ Explicitly, suppose that we have $F=F(p)$ with $F^{\prime}(p)<0, \lim _{p \rightarrow 0} F(p)=\infty$, and $F^{0}<F(M)$. Then, following the same steps as in Section 4, we obtain that the steady state value of $p$ will be given by

$$
p(\theta, f)=\frac{\lambda \gamma f \theta q(\theta) M}{\lambda+\mu+\left[1+\frac{\lambda \gamma}{\mu}(1-f)\right] \theta q(\theta)},
$$

which is increasing in both $\theta$ and $f$.

For given $f$, equation (21) and the condition

$$
F(p(\theta, f))=F
$$

solve for a candidate steady state equilibria of our economy in the $\theta-F$ space. However (13) and (33) imply that multiple equilibria can emerge. This is because there is a strategic complementarity in the choice of life cycle variable $f$. Suppose $f$ is low, then $p$ is low, so $F$ is high, reflecting that the market for fast growing companies is not very liquid. But then choosing a low $f$ can indeed be optimal. With similar arguments one can show the sustainability of an equilibrium with high $f$. More formally, notice that with $f=0$, we have $p=0, F$ goes to infinity, so $f=0$ is an equilibrium. On

\footnotetext{
${ }^{29}$ See Smith et al. (1998) for a detailed description of the history and functioning of Nasdaq.

${ }^{30}$ See Subrahmanyam and Titman (1999) for an information-based microfoundation of liquidity externalities.
} 
the other hand, if assuming $f=1$, it happens that the candidate equilibrium value of $\theta$ satisfies $F(p(\theta, 1))<F^{d}(\theta)$, then there is also an equilibrium with $f=1$. These two equilibria are Pareto-ranked and the one with a smaller flotation cost associates with larger welfare. Therefore, if the economy is blocked in the worse equilibrium, the analysis delivers a rational for why subsidizing IPOs might be welfare improving. ${ }^{31}$

Actually, in the presence of liquidity externalities, the rationale for subsidizing IPOs is more general and does not need to rely on multiple equilibria. To see this, consider a simple generalization of our model in which start-ups, indexed by $j$, differ in their cost of going public, $F_{j}(p)$, with $F_{j}^{\prime}(p)<0$. Then, start-ups will decide to go public if their $F_{j}(p)$ is below the critical value $F^{d}(\theta)$. However, since each start-up does not internalize the effects of its decision on the cost of going public of the others, the equilibrium number of IPOs will be suboptimal. In other words, the critical value $F^{d}(\theta)$ would be below the socially optimal one and a subsidy to IPOs would reduce the gap between the two.

\subsection{Investment banking}

In this last extension we analyze how the cost of going public and the financial life cycle of start-ups interact with the development of investment banking activities. We associate these activities with the gathering of information regarding the profitability of start-ups and we measure their output by the now endogenous rate $\lambda$ at which unknown start-ups discover their type.

Let $C(\lambda)$ denote the flow cost (in income units) that a firm must incur in order to induce an instantaneous rate of arrival of information about its type $\lambda$. We assume that $C(\lambda)$ is increasing and satisfies the standard Inada conditions. ${ }^{32}$ Moreover, we assume that this cost is verifiable so that $\lambda$ can

\footnotetext{
${ }^{31}$ An explicit evaluation of the gains from moving from an equilibrium with $f=0$ to one with $f=1$ is, however, complicate since during the transition the endogenous variables $\theta$ and $f$ would be functions of the state variables of the system, $u_{t}, d_{t}$, and $p_{t}$. Moreover, the costs of transition might render the net welfare gains from switching to the "good" equilibrium negative.

${ }^{32}$ We have modelled the costs of producing $\lambda$ as internal to the firm. Alternatively, we might have assumed that there is a perfectly competitive investment-banking sector that provides its services to firms at a given price per unit of $\lambda$. If this sector faces marginal costs which are constant in the number of firms that it serves (quantities) but increasing
} 
be written into the contract between the entrepreneur and the monitor at the beginning of their relationship.

As the entrepreneur has no own wealth, $C(\lambda)$ is financed by the monitor, whose value of the relationship while firm type remains unknown is now given by

$$
\begin{aligned}
\rho L^{u}= & -C(\lambda)+\lambda\left[\gamma f(1-\alpha)\left(R^{d}-F\right)+\gamma(1-f) L^{d}+(1-\gamma)(1-\alpha) Q-L^{u}\right] \\
& +\mu\left[(1-\alpha) R^{m}-L^{u}\right]+[\lambda+\mu-\lambda \gamma(1-f)] V .
\end{aligned}
$$

We neglect potential hold-up problems by assuming that the initial agreement on $\lambda \in[0, \infty)$ is not subject to renegotiation. The initial bargaining problem is extended to:

$$
\max _{\alpha, f, \lambda}\left(B^{u}-U\right)^{\beta}\left(L^{u}-1-V\right)^{1-\beta}
$$

and the new expression for the surplus is

$$
\begin{aligned}
S= & \frac{\lambda}{\lambda+\mu+\rho}\left[\gamma f\left(R^{d}-F\right)+\gamma(1-f)\left(R^{w}-\frac{\rho}{\mu+\rho} V\right)+(1-\gamma) Q\right] \\
& +\frac{\mu}{\lambda+\mu+\rho} R^{m}-\frac{1}{\lambda+\mu+\rho} C(\lambda)-\frac{\rho}{\lambda+\mu+\rho} V-U-1 .
\end{aligned}
$$

The solution to the bargaining problem for $\alpha$ and $f$ implies the same conditions (9), (10) and (13) as in the basic model. Moreover the first order condition for maximizing $S$ with respect to $\lambda$ can be written as

$$
C^{\prime}(\lambda)=\left[\gamma f\left(R^{d}-F\right)+\gamma(1-f)\left(R^{w}-\frac{\rho}{\mu+\rho} V\right)+(1-\gamma) Q\right]-U-1-S .
$$

Using (35) and following the same steps as in Section 4.1, the equilibrium surplus can be compactly expressed as

$$
S(\theta, \lambda)=\frac{\mu\left(R^{m}-1\right)+\lambda C^{\prime}(\lambda)-C(\lambda)-\rho}{\mu+\rho+(1-\beta) \theta q(\theta)},
$$

where $\theta$ and $\lambda$ are the only endogenous variables. Given (36), the free entry condition for entrepreneurs becomes

$$
\beta q(\theta) S(\theta, \lambda)=c
$$

in the intensity of the analysis $\lambda$ (quality), the main conclusions would be identical. 
while, after accounting for the equilibrium choice of $f$, the first order condition for $\lambda$ can be rewritten as

$$
C^{\prime}(\lambda)=\left\{\gamma R^{d}-\gamma \min \left[F, F^{d}(\theta)\right]+(1-\gamma) Q-1\right\}-\frac{c}{\beta q(\theta)},
$$

where $F^{d}(\theta)$ was defined in (19).

Equations (36)-(38) solve the model in the $\theta-\lambda$ space. The first two define a positive relation between $\theta$ and $\lambda$ : the larger the intensity in gathering information $\lambda$, the larger is the surplus of an entrepreneur-monitor relationship $S$ and, thus, the induced level of credit rationing $\theta$. In contrast, the first order condition (38) establishes a negative relation between $\theta$ and $\lambda$. It reflects that, in equilibrium, a larger $\theta$ associates with a larger $S$ and, consequently, with a lower capital gain from discovering the firm's type. (Notice that such discovery makes the relationship to change status or to sever.) The solution is therefore unique. After solving for $\theta,(13)$ and (19) determine the equilibrium financial life cycle $f$. It can then be checked that increasing the flotation cost $F$ shifts (38) to the left thus reducing both the level of credit rationing $\theta$ and the intensity of investment banking activities $\lambda$.

This analysis has two interesting implications. First it predicts a negative correlation between the intensity of investment-banking activities and the cost of going public. It also shows, see (35), that the larger the rents generated by the entrepreneur-monitor relationship the lower is the incentive for gathering information that may eventually sever the relationship. Interestingly, it can be shown that the size of these rents is minimized under the efficient sharing rule, when the value of informed capital is maximized. Therefore, an inefficient allocation of resources generates vested interests in ongoing relations that hamper the development of investment-banking activities thus reducing the amount of information about start-ups, delaying the recycling of informed capital, and diminishing the size and the scope of the stock market.

\section{Conclusions}

We have analyzed how securities markets interact with informed capital financing in promoting growth. We have focused on the financial problem 
of fast growing start-ups. The implicit assumption has been that, during a technological revolution in which innovation requires the creation of new independent businesses, start-ups are the seed of future growth. The model implies that institutional differences in securities markets may produce crosscountry differences in the patterns of firm creation and in the speed at which new technologies are adopted. For example the lack of a well developed market for small fast growing companies in Europe might help explain why Europe has fallen behind the US in taking advantage of the IT revolution and, more generally, in the adoption of high-tech technologies. ${ }^{33}$ Furthermore, by endogenizing various aspects of the economy's financial structure (firms' life cycle, market liquidity, investment banking) we have identified possible causes of financial underdevelopment and potential policy responses. In addition our model provides a framework for an explicit evaluation of the welfare implications of these policies.

For analytical convenience we have abstracted from the details of the financing problem of mature firms. Yet the choice between informed capital financing and securities market financing remains relevant during the whole life of the firm. Analyzing how this choice affects the ability of mature companies to innovate and grow represents a challenging call for further research. In our model the stock market stimulates growth because it recycles informed capital. Going public might however hamper the process of innovation of mature companies. For example, the pressure of market investors might either reduce the time horizon of management, negatively affecting R\&D investment, or force the management to disclose unwanted information, thus reducing the appropriability of innovations.

\footnotetext{
${ }^{33}$ See OECD (1994). Pagano et al. (1998) note that the typical newly listed company is much larger and older in Italy than in the US. They attribute this to the lack of enforcement of minority property rights which makes it more difficult for young and small companies to capture investors' trust.
} 


\section{Appendix}

\section{Impossibility of stock market financing without paying $F$}

To rule out the possibility that entrepreneurs finance their start-ups through the stock market without paying $F$, it suffices to guarantee that even if the firm were known to be good such an arrangement would not be feasible. Consider a good start-up and let $\tilde{\alpha}$ describe a contract whereby the entrepreneur and some investor get some fractions $\tilde{\alpha}$ and $1-\tilde{\alpha}$, respectively, of the value of the firm at its maturity, $Y$. Under such contract, the entrepreneur's value from running the firm, $\Pi$, is given by

$$
\rho \Pi=\max \{b, \mu(\tilde{\alpha} Y-\Pi)\}
$$

and the contract $\tilde{\alpha}$ provides incentives for effort if and only if

$$
\tilde{\alpha} \geq \frac{\mu+\rho}{\mu Y} \frac{b}{\rho}
$$

Let $D$ denote the value of the investor's stake in the project when this condition holds. Then,

$$
\rho D=[(1-\tilde{\alpha}) Y-D]
$$

and he will be willing to finance the project only if $D \geq 1$, that is,

$$
(1-\tilde{\alpha}) \geq \frac{\mu+r}{\mu Y}
$$

However, the inequalities (39) and (40) are not compatible if $b$ is too large. Specifically, if

$$
\frac{b}{\rho}>\frac{\mu Y}{\mu+\rho}-\frac{\mu+r}{\mu+\rho}
$$

as we assume.

\section{Results on efficiency}

In this section we prove our results on efficiency. We start obtaining the dynamics of the costate variables $z^{u}$ and $z^{d}$ that appear in (26); time indices 
are omitted, for brevity. Differentiating (26) with respect to $u, d$, and time, we obtain

$$
\begin{aligned}
\dot{z}^{u}= & {[\lambda+\mu+\rho+\theta q(\theta)] z^{u}-\lambda \gamma(1-f) z^{d}-\lambda\left[\gamma f\left(R^{d}-F\right)+(1-\gamma) Q\right] } \\
& -\mu R^{m}-[c \theta+\theta q(\theta)] \\
\dot{z}^{d}= & \theta q(\theta) z^{u}+(\mu+\rho) z^{d}-\mu Y-[c \theta+\theta q(\theta)]
\end{aligned}
$$

where $\dot{z}^{u}$ and $\dot{z}^{d}$ are the derivatives with respect to time of $z^{u}$ and $z^{d}$ respectively. These equations define a linear system with constant coefficients in $z^{u}$ and $z^{d}$ that is globally unstable. Hence $z^{u}$ and $z^{d}$ are two jump variables that must satisfy the condition $\dot{z}^{u}=\dot{z}^{d}=0$ at any point in time. Using (42) and (43) this implies

$$
\begin{aligned}
z^{d} & =\frac{(\lambda+\mu+\rho)[\mu Y+c \theta+\theta q(\theta)]+\theta q(\theta)[\mu Y-A(f)]}{(\mu+\rho)[\lambda+\mu+\rho+\theta q(\theta)]+\lambda \gamma(1-f) \theta q(\theta)}, \\
z^{u} & =\frac{\lambda \gamma(1-f)[\mu Y+c \theta+\theta q(\theta)]+(\mu+\rho)[c \theta+\theta q(\theta)+A(f)]}{(\mu+\rho)[\lambda+\mu+\rho+\theta q(\theta)]+\lambda \gamma(1-f) \theta q(\theta)},
\end{aligned}
$$

where $A(f)=\lambda\left[\gamma f\left(R^{d}-F\right)+(1-\gamma) Q\right]+\mu R^{m}$.

1. Efficiency of the equilibrium financial life cycle Differentiating (26) with respect to $f$ we find that

$$
\frac{d W}{d f}=\frac{\lambda \gamma}{\rho}\left(R^{d}-F-z^{d}\right) u_{t}
$$

which, given (44), has the same sign as the quantity

$$
\begin{aligned}
B= & {[\lambda+\mu+\rho+\theta q(\theta)](\mu+\rho)\left(R^{d}-F-R^{w}\right)+\theta q(\theta) A(1) } \\
& -(\lambda+\mu+\rho)[c \theta+\theta q(\theta)] .
\end{aligned}
$$

To evaluate the sign of $B$, consider first the case where in equilibrium $F<$ $F^{d}(\theta)$, so $f=1$. Then (20) and (21) allow us to write

$$
A(1)=\frac{[\lambda+\mu+\rho+(1-\beta) \theta q(\theta)] c}{\beta q(\theta)}+(\lambda+\mu+\rho) .
$$

Substituting back in (47) and using (19), we find that

$$
\frac{B}{(\mu+\rho)[\lambda+\mu+\rho+\theta q(\theta)]}=F^{d}(\theta)-F>0 .
$$


Consider next the case where in equilibrium $F>F^{d}(\theta)$, so $f=0$. Then (20) and (21) allow us to write

$$
A(1)=\frac{[\lambda+\mu+\rho+(1-\beta) \theta q(\theta)] c}{\beta q(\theta)}+(\lambda+\mu+\rho)+\lambda \gamma\left[F^{d}(\theta)-F\right] .
$$

Substituting back in (47) and using (19), we finally obtain that

$$
\frac{B}{(\mu+\rho)[\lambda+\mu+\rho+\theta q(\theta)]+\lambda \gamma \theta q(\theta)}=F^{d}(\theta)-F<0,
$$

which completes the proof of the result stated in $(27)$.

2. Bargaining power and efficiency Deriving (26) with respect to $\theta$ we find that

$$
\frac{d W}{d \theta}=\frac{1}{\rho}\left\{\left[\eta q(\theta)\left(z^{u}-1\right)-c\right]\left(M-d_{t}-u_{t}\right)+\frac{d z^{u}}{d \theta} \dot{u}_{t}+\frac{d z^{d}}{d \theta} \dot{d}_{t}\right\}
$$

where $\eta=\frac{1}{q(\theta)} \frac{d[\theta q(\theta)]}{d \theta}$ is the elasticity of the matching function with respect to the number of entrepreneurs. When (50) is evaluated in the steady state, $\dot{u}=\dot{d}=0$, it has the same sign as $\eta q(\theta)\left(z^{u}-1\right)-c$. To evaluate this sign, consider first the case where in equilibrium $F<F^{d}(\theta)$, so $f=1$. Using (45) evaluated at $f=1$ together with (48), we find that the sign is the same as that of

$$
(\mu+\rho)[\lambda+\mu+\rho+\theta q(\theta)] \frac{c}{\beta}(\eta-\beta) .
$$

Consider next the case where $F>F^{d}(\theta)$, so $f=0$. Then, using (45) evaluated at $f=0$ together with equations (19)-(21), we obtain that

$$
\eta q(\theta)\left(z^{u}-1\right)=\frac{\{(\mu+\rho)[\lambda+\mu+\rho+\theta q(\theta)]+\lambda \gamma \theta q(\theta)\} c \eta}{(\mu+\rho) \beta[\lambda+\mu+\rho+\theta q(\theta)]+\lambda \gamma \beta \theta q(\theta)} .
$$

But this means that $\frac{d W}{d \theta}$ has the same sign as

$$
\{(\mu+\rho)[\lambda+\mu+\rho+\theta q(\theta)]+\lambda \gamma \theta q(\theta)\} \frac{c}{\beta}(\eta-\beta),
$$

which completes the proof of the result stated in (28). 
3. Value of informed capital and efficiency We show that the value of informed capital $V$ is maximized at $\beta=\eta$. Differentiating (18) with respect to $\beta$ we obtain that

$$
\frac{d V}{d \beta}=\frac{(1-\beta) c}{\rho \beta} \cdot \frac{d \theta}{d \beta}-\frac{c \theta}{\rho \beta^{2}}
$$

If in equilibrium $F<F^{d}(\theta),(20)$ and (21) imply

$$
\frac{d \theta}{d \beta}=\frac{[\lambda+\mu+\rho+\theta q(\theta)] \theta}{\beta[(1-\eta)(\lambda+\mu+\rho)+(1-\beta) \theta q(\theta)]},
$$

so

$$
\frac{d V}{d \beta}=\frac{c \theta(\lambda+\mu+\rho)}{(1-\eta)(\lambda+\mu+\rho)+(1-\beta) \theta q(\theta)} \cdot \frac{\eta-\beta}{\rho \beta^{2}},
$$

which is positive (negative) for $\beta$ smaller (greater) than $\eta$. On the other hand, if in equilibrium $F>F^{d}(\theta),(20)$ and (21) imply

$$
\frac{d \theta}{d \beta}=\frac{[(\mu+\rho)(\lambda+\mu+\rho)+\theta q(\theta)(\lambda \gamma+\mu+\rho)] \theta}{\beta[(\mu+\rho)(\lambda+\mu+\rho)(1-\eta)+(\lambda \gamma+\mu+\rho)(1-\beta) \theta q(\theta)]},
$$

so

$$
\frac{d V}{d \beta}=\frac{c \theta(\mu+\rho)(\lambda+\mu+\rho)}{(\mu+\rho)(\lambda+\mu+\rho)(1-\eta)+(\lambda \gamma+\mu+\rho)(1-\beta) \theta q(\theta)} \cdot \frac{\eta-\beta}{\rho \beta^{2}},
$$

which is also positive (negative) for $\beta$ smaller (greater) than $\eta$. Hence $V$ attains a maximum when $\beta=\eta$. 


\section{References}

[1] Aghion, P. and Howitt P. (1998), Endogenous Growth Theory, The MIT Press, Cambridge, Massachusetts.

[2] Aghion, P. and Tirole J. (1994), "The Management of Innovation", Quarterly Journal of Economics, 109, 1185-1209.

[3] Baltensperger, E. (1976), "The Borrower-Lender Relationship, Competitive Equilibrium and the Theory of Hedonic Prices", American Economic Review, 66, 401-405

[4] Black, B. and Gilson, R. (1998), "Venture Capital and the Structure of Financial Markets: Banks Versus Stock Markets", Journal of Financial Economics, 47, 243-277.

[5] Caballero, R. and Jaffe, A. (1993), "How High are the Giants Shoulders: An Empirical Assessment of Knowledge Spillovers and Creative Destruction in a model of Economic Growth". In NBER Macroeconomics Annual 1993, edited by Blanchard, O. and Stanley, F. Cambridge Mass.: MIT Press.

[6] Diamond, D. (1991), "Monitoring and Reputation: The Choice between Bank Loans and Directly Placed Debt", Journal of Political Economy, 99, 689-721.

[7] European Commission (1998), "Risk Capital: A Key to Job Creation in the European Union ", Communication of The European Commission, April.

[8] Greenwood, J. and Jovanovic, B. (1990), "Financial Development, Growth, and the Distribution of Income", Journal of Political Economy, 98, 1076-1107.

[9] Greenwood, J. and Jovanovic, B. (1999), "The IT Revolution and the Stock Market", American Economic Review Papers and Proceedings, 89, 49-95.

[10] Hobijn, B. and Jovanovic, B. (1999) "The IT Revolution and the Stock Market: Preliminary Evidence", mimeo, New York University, http://www.econ.nyu.edu/user/jovanovi/index.htm. 
[11] Holmstrom , B. and Tirole, J. (1997), "Financial Intermediation, Loanable Funds, and the Real Sector", Quarterly Journal of Economics, 112, 663-691.

[12] Hosios, A. (1990), "On the Efficiency of Matching and Related Models of Search and Unemployment", Review of Economic Studies, 57, 279-298.

[13] Kortum, S. and Lerner, J. (1998), "Stronger Protection or Technological Revolution: What is Behind the Recent Surge in Patenting?", CarnegieRochester Conference Series on Public Policy, 48, 247-304.

[14] Krusell,P., Ohanian, L., Rios-Rull, V. and Violante, G. (1999), "CapitalSkill Complementarity and Inequality: A Macroeconomic Analysis", Econometrica, forthcoming.

[15] Kumar, K., Rajan, R. and Zingales L. (1999) "What Determines Firm Size?", NBER Working Paper, n. 7208.

[16] Levine, R. (1997) "Financial Development and Economic Growth: Views and Agenda", Journal of Economic Literature, 35, 688-726.

[17] Levine, R. and Zervos, S. (1998) "Stock Markets, Banks, and Economic Growth", American Economic Review, 88, 537-558.

[18] OECD, (1994), "Technological Change and Innovation", in OECD Jobs Study, Part I, chapter 4.

[19] Pagano, M., Panetta, F. and Zingales, L. (1998), "Why Do Companies Go Public? An Empirical Analysis", Journal of Finance, 53, 27-64.

[20] Pissarides, C. A. (1990), Equilibrium Unemployment Theory, Oxford: Basil Blackwell.

[21] Petersen, M. and Rajan, R. (1994), "The Benefits of Lending Relationships: Evidence from Small Business Data", Journal of Finance, 49, $3-37$.

[22] Rajan, R. (1992), "Insiders and Outsiders: the Choice between Informed and Arm's-Length Debt", Journal of Finance, 47, 1367-1400.

[23] Rajan, R. and Zingales, L. (1998), "Financial Dependence and Growth", American Economic Review, 88, 559-586. 
[24] Smith, J., Selway J. and McCormick, T. (1998), "The NASDAQ Stock Market: Historical Background and Current Operation", NASD Working Paper 98-01, August.

[25] Subrahmanyam, A and Titman, S. (1999), "The Going Public Decision and the Development of Financial Markets", Journal of Finance, 54, 1045-1082. 